\title{
FREQUENCY CHARACTERISTICS OF BENGALI AND TAMIL VOWELS IN VARYING SPEAKING RATE
}

\author{
Dr.Kala Samayan ${ }^{1}$, Elanthendral $\mathrm{C}^{2}$, Dr.Anamika Hui ${ }^{3}$ \\ ${ }^{I}$ Dr. Kala Samayan, Associate Professor, Department of Audiology \& Speech Language Pathology, \\ SRM MCH \& RC, SRMIST, SRM University, Kattankulathur, Chennai-603 203. Tamil Nadu, India \\ ${ }^{2}$ Elanthenral C, Assistant Professor, Department of Audiology \& Speech Language Pathology, SRM \\ MCH \& RC, SRMIST, SRM University, Kattankulathur, Chennai-603 203. Tamil Nadu, India \\ ${ }^{3}$ Dr Anamika Hui, Audiologist and Speech language Pathologist, HCDLC, Navi, Mumbai, India
}

Article DOI: https://doi.org/10.36713/epra8112 DOI No: 10.36713/epra8112

\begin{abstract}
Speech has its unique importance as the primary means by which language is expressed in all human cultures. It is a fluid phenomenon, characterized by rapid changes in articulation and its acoustic product. Vowels can differ in acoustic analysis in various aspects because the speech code varies with language, dialect, age and sex and specific physiological constraints of the speaker. Keeping in view that rate brings changes in speech and vowels being more acoustically approachable, it is assumed that there would be changes in vowel acoustics with change in rate of speech. The present study is aimed at understanding the influence of rate of speech on formant frequency of vowel acoustics in two different languages - Bengali (Indo-Aryan) and Tamil (Dravidian). The subjects for the study were grouped based on languages Group I consisted of 10 males with native language as Bengali, Group II consisted of 10 males with native language as Tamil in the age range of 18 to 28 years. The results shows that the formant frequency of three similar vowels of /a/, /i/ and $/ u /$ in both languages and non-similar/different vowel of $/ \partial /$ in Bengali and $/ \Lambda /$ in Tamil indicates significant difference in varying speaking rate. The differences in vowel acoustics in varying speaking rate in Tamil and Bengali showed higher duration to read the passage in normal than fast rate.
\end{abstract}

KEYWORDS: Formant frequency, vowel acoustics, Tamil and Bengali

\section{INTRODUCTION}

Speech has its unique importance as the primary means by which language is expressed in all human cultures. It is a fluid phenomenon, characterized by rapid changes in articulation and its acoustic product. The dynamics of speech poses a great challenge to its analysis, and one solution has been to make measurements at selected time points thought to represent targets, goals, or steady states. This approach has been taken with vowel formant measurements, which have a long history in the study of speech production, especially because formant descriptions are suited to articulatory interpretations of acoustic data and are therefore fundamental to discovery of features in articulatory-acoustic conversion. (Kent, 2018)

'Speech is movement made audible and explained that the movements of the speech organs - structures such as the tongue, lips, jaw, velum and vocal folds result in sound patterns that are perceived by the listener. These movements are used to produce consonants and vowels. Vowels are the sounds produced with laryngeal vibration under relatively open vocal tract that is shaped to produce particular patterns of resonances so that the entire vocal tract functions as a filter or frequency selective transmission system. The vowels are also the simplest sounds to analyze and describe acoustically.

Vowel sound exhibits spectral energy maxima in frequency ranges that correspond to the resonances of the vocal tract during speech production. These spectral energy maxima are known as formants. A formant is a 
local maximum in the vocal tract transfer function. Vowels often have been characterized with first three formant frequencies.

Tsao, Weismer and Iqbal (2006) studied the effect of intertalker speech rate variation on acoustic vowel space. They found that within talkers, faster speaking rates result in the compression of the vowel space relative to that measured for slower rates. As a result when the habitual speaking rate was differed significantly, there was no difference observed in the average size of the vowel space for slow vs fast talkers. No relationship across talkers between vowel duration and formant frequencies was found as well. The intertalker variability of the vowel spaces was found to be greater for slow talkers than the fast talkers for both males and females (Dietrich, 2019). Keeping in view that rate brings changes in speech and vowels being more acoustically approachable, it is assumed that there would be changes in vowel acoustics with change in rate of speech. The present study is aimed at understanding the influence of rate of speech on vowels acoustics in two different languages - Bengali (Indo-Aryan) and Tamil (Dravidian). The present study included only males because the high frequency voices especially more than $400 \mathrm{~Hz}$ (women and children) usually suffer estimation inaccuracy, the spectral lines become so wide that a reconstruction of the spectral envelop from the available harmonic amplitudes fails to show the second formant. This failure does not mean that the formant is not present, it is just not detected. So, to avoid this inaccuracy, male data has been used in this study.

\section{SYMBOLIC NOTATIONS USED IN THE STUDY}

- Formant frequency is symbolized as fi, where $\mathrm{f}$ is the center frequency of the formant and $\mathrm{i}$ is the formant number.

- For example, ff1 is the first formant frequency. The formant frequency for a particular vowel is expressed as fi $/ \mathrm{x} /$ where fi is the formant frequency for formant $\mathrm{i}$ and $\times$ is a phonetic symbol.

- For example, the first-formant frequency of vowel /i/ is expressed as $\mathrm{f} 1 / \mathrm{i} /$.

- Bengali normal rate of speech is indicated with the acronym BNR and Bengali fast rate of speech is indicated with the acronym BFR.

- Tamil normal rate of speech is indicated with the acronym TNR and Bengali fast rate of speech is indicated with the acronym TFR

\section{AIM OF THE STUDY}

To understand the acoustical differences with respect to formant frequency in two different languages, Tamil and Bengali in varying speaking rates.

\section{OBJECTIVES OF THE STUDY}

1) To compare vowel formant frequency $(\mathrm{m} f 1, m f 2)$ in normal and fast rate in Tamil

2) To compare vowel formant frequency $(\mathrm{m} f 1, m f 2)$ in normal and fast rate in Bengali

3) To document differences in vowel acoustics in varying speaking rate in Tamil and Bengali

4) To document differences in non-similar vowel acoustics in varying speaking rate in Tamil and Bengali

5) To compare of mean rate of speech in varying speaking rate in Bengali and Tamil

\section{METHODOLOGY}

Subjects

The subjects for the study were grouped based on languages - Group I consisted of 10 males with native language as Bengali, Group II consisted of 10 males with native language as Tamil. Subjects of both groups satisfied the following criteria. 1) All subjects were in age range of 18-28years. 2) No history of any speech, language and hearing disorders. 3) All participants were graduate student volunteers from West Bengal and Tamil Nadu.

\section{Materials}

All-phoneme passages in Bengali and Tamil were developed with 225 syllables and 372 syllables in each respectively. These passages served as reading material for the study.

\section{Instrumentation}

Tape SONY R 30 Digital Recorder and PRAAT software version 4.3. 


\section{Procedure}

The subjects of Group I had to read Bengali passage and subjects of Group II had to read Tamil passages. Three recordings of reading from each subject under two conditions were collected. In condition one (Normal rate), the subjects were instructed to read the passage at their normal rate of speech. In condition two (Fast rate), the subjects were instructed to read the passage at twice their normal rate of speech. All the recordings were done in a quiet room. The samples were recorded into Tape SONY R 30 Digital Recorder. The samples were transcribed by Bengali and Tamil speaking speech-language pathologists to get the rate of speech.

\section{Acoustic Analysis}

The audio-recordings were digitized into the PC using the recording facility of PRAAT program. The samples were digitized at $22050 \mathrm{~Hz}$ sampling frequency and stored as wave files. Using the edit and spectrograph module of PRAAT, the following parameters were extracted for the inter-consonantal vowels with similar context /a/, /i/, /u/ and / / / in Bengali and /a/, /i/, /u/ and / $/$ in Tamil. /a/, /i/ and /u/ were selected as a common vowel to both the languages $. / \mathrm{J} /$ in Bengali and $/ N$ in Tamil were selected as unique vowels in the language. The parameters assessed in both the languages for all the above mentioned vowels were Mean F1, Mean F2, transition duration, extent of transition to the following consonants and speed of transition.

\section{Rate of Speech Analysis}

The audio-recordings were digitized and analyzed from EDIT program of PRAAT to calculate the total number of syllables and time taken for reading the passages for three trials of both normal rate and fast rate. Rate of speech difference is documented with time taken for reading 225 syllables in Bengali and 372 syllables in Tamil respectively.

\section{RESULTS}

The present study aimed at comparing the mean formant frequencies of vowels in two different languages in varying speaking rate.

Objective 1: To compare vowel formant frequency $(\mathrm{m} f 1, m f 2)$ in normal and fast rate in Tamil

Table 1.1. Comparison of vowel mean first formant frequency $(\mathrm{mf} 1)$ of $/ \mathrm{a} / \mathrm{in}$ normal and fast rate in Tamil

\begin{tabular}{|l|c|c|c|c|c|}
\hline \multicolumn{7}{|c|}{ One-Sample Statistics } \\
\hline & Nean & $\begin{array}{c}\text { Std. } \\
\text { Deviation }\end{array}$ & t & $\begin{array}{c}\text { Sig. } \\
\text { (2-tailed) }\end{array}$ \\
\hline Mean first formant frequency /a/ Tamil normal rate & 10 & 683.8620 & 84.97163 & 25.450 & .000 \\
\hline Mean first formant frequency /a/ Tamil fast rate & 10 & 1180.1870 & 1740.56682 & 2.144 & .061 \\
\hline
\end{tabular}

The above table indicates that the there is a significant difference between first formant frequency of /a/ in Tamil normal and fast rate

Table 1.2 Comparison of vowel formant frequency $(\mathrm{mf} 2)$ of /a/ in normal and fast rate in Tamil One-Sample Statistics

\begin{tabular}{|l|c|c|c|c|c|}
\hline & N & Mean & $\begin{array}{c}\text { Std. } \\
\text { Deviation }\end{array}$ & $\begin{array}{c}\text { t } \\
\text { Sig. } \\
\text { (2-tailed) }\end{array}$ \\
\hline $\begin{array}{l}\text { Mean second formant frequency /a/ Tamil normal } \\
\text { rate }\end{array}$ & 10 & 1864.4320 & 246.16291 & 23.951 & .000 \\
\hline \begin{tabular}{l} 
Mean second formant frequency /a/ Tamil fast rate \\
\hline
\end{tabular} & 10 & 1887.4250 & 250.41870 & 23.834 & .000 \\
\hline
\end{tabular}

The above table indicates that the there is a significant difference between second formant frequency of /a/ in Tamil normal and fast rate 
Table 1.3 Comparison of vowel formant frequency (mf1) of /i/ in normal and fast rate in Tamil One-Sample Statistics

\begin{tabular}{|l|c|c|r|r|r|}
\hline & N & Mean & $\begin{array}{c}\text { Std. } \\
\text { Deviation }\end{array}$ & $\begin{array}{c}\text { Sig. } \\
(\mathbf{2 t a i l e d )}\end{array}$ \\
\hline Mean first formant frequency /i/ Tamil normal rate & 10 & 567.2090 & 91.70438 & 19.559 & .000 \\
\hline Mean first formant frequency /i/ Tamil fast rate & 10 & 546.5750 & 57.18234 & 30.226 & .000 \\
\hline
\end{tabular}

The above table indicates that the there is a significant difference between first formant frequency of /i/ in Tamil normal and fast rate

Table 1.4 Comparison of vowel formant frequency $(\mathrm{mf} 2)$ of /i/ in normal and fast rate in Tamil One-Sample Statistics

\begin{tabular}{|c|c|c|c|c|c|}
\hline \multicolumn{6}{|c|}{ One-Sample Statistics } \\
\hline & $\mathbf{N}$ & Mean & $\begin{array}{c}\text { Std. } \\
\text { Deviation }\end{array}$ & $\mathbf{t}$ & Sig. (2-tailed) \\
\hline Mean second formant frequency /i/ Tamil normal rate & 10 & 2048.4250 & 105.80053 & 61.225 & .000 \\
\hline Mean second formant frequency /i/ Tamil fast rate & 10 & 2057.9500 & 131.98264 & 49.308 & .000 \\
\hline
\end{tabular}

The above table indicates that the there is a significant difference between second formant frequency of /i/ in Tamil normal and fast rate

Table 1.5 Comparison of vowel formant frequency $(\mathrm{mf1})$ of $/ \mathrm{u} / \mathrm{in}$ normal and fast rate in Tamil One-Sample Statistics

Mean first formant frequency /u/ Tamil normal rate

Mean first formant frequency / $\mathrm{u} /$ Tamil fast rate

\begin{tabular}{|c|l|r|r|c|}
\hline $\mathbf{N}$ & Mean & Std. Deviation & \multicolumn{1}{c|}{ t } & Sig. (2-tailed) \\
\hline 10 & 596.8590 & 107.17629 & 25.450 & .000 \\
\hline 10 & 614.6500 & 154.68065 & 2.144 & .061 \\
\hline
\end{tabular}

The above table indicates that the there is a significant difference between first formant frequency of / $\mathrm{u} / \mathrm{in}$ Tamil normal and fast rate

Table 1.6 Comparison of vowel formant frequency $(\mathrm{mf} 2)$ of $/ \mathrm{u} / \mathrm{in}$ normal and fast rate in Tamil

\begin{tabular}{|l|c|c|c|c|c|}
\hline \multicolumn{7}{|c|}{ One-Sample Statistics } & t & Sig. (2-tailed) \\
\hline $\begin{array}{l}\text { Mean second formant frequency /u/ Tamil normal } \\
\text { rate }\end{array}$ & 10 & 2031.5110 & 74.35716 & 86.397 & .000 \\
\hline Mean second formant frequency /u/ Tamil fast rate & 10 & 2025.7090 & 114.64773 & 55.874 & .000 \\
\hline
\end{tabular}

The above table indicates that the there is a significant difference between second formant frequency of /u/ in

Tamil normal and fast rate

\section{Objective 2:}

To compare vowel formant frequency $(\mathrm{m} f 1, \mathrm{mf2})$ in normal and fast rate in Bengali Table 2.1 Comparison of vowel formant frequency (mf1) of /a/ in normal and fast rate in Bengali One-Sample Statistics

The above table indicates that the there is a significant difference between first formant frequency of /a/ in

Bengali normal and fast rate 
Table 2.2 Comparison of vowel formant frequency $(\mathrm{mf} 2)$ of /a/ in normal and fast rate in Bengali One-Sample Statistics

\begin{tabular}{|l|c|c|c|c|c|}
\hline & N & Mean & $\begin{array}{c}\text { Std. } \\
\text { Deviation }\end{array}$ & $\begin{array}{c}\text { Sig. } \\
(\mathbf{2} \text { tailed) }\end{array}$ \\
\hline Mean second formant frequency /a/ Bengali normal rate & 10 & 1575.2700 & 247.74999 & 20.107 & .000 \\
\hline Mean second formant frequency /a/ Bengali fast rate & 10 & 1571.1400 & 176.57736 & 28.137 & .000 \\
\hline
\end{tabular}

The above table indicates that the there is a significant difference between second formant frequency of /a/ in Bengali normal and fast rate

Table 2.3 Comparison of vowel formant frequency $(\mathrm{mf1})$ of /i/ in normal and fast rate in Bengali One-Sample Statistics

\begin{tabular}{|c|c|c|c|c|c|}
\hline \multicolumn{6}{|c|}{ One-Sample Statistics } \\
\hline & $\mathbf{N}$ & Mean & $\begin{array}{c}\text { Std. } \\
\text { Deviation }\end{array}$ & $\mathbf{t}$ & $\begin{array}{c}\text { Sig. } \\
\text { (2-tailed) }\end{array}$ \\
\hline Mean first formant frequency /i/ Bengali normal rate & 10 & 406.0300 & 28.92362 & 44.392 & .000 \\
\hline Mean first formant frequency /i/ Bengali fast rate & 10 & 415.1300 & 22.42514 & 58.540 & .000 \\
\hline
\end{tabular}

The above table indicates that the there is a significant difference between first formant frequency of /i/ in Bengali normal and fast rate

Table 2.4 Comparison of vowel formant frequency $(\mathrm{mf} 2)$ of /i/ in normal and fast rate in Bengali

\begin{tabular}{|l|r|r|r|r|r|}
\hline \multicolumn{3}{|c|}{ One-Sample Statistics } & Mean & $\begin{array}{c}\text { Std. } \\
\text { Deviation }\end{array}$ & $\begin{array}{c}\text { t } \\
\text { Sig. } \\
(2-t a i l e d)\end{array}$ \\
\hline $\begin{array}{l}\text { Mean second formant frequency /i/ Bengali normal } \\
\text { rate }\end{array}$ & 10 & 1651.0100 & 312.49287 & 16.707 & .000 \\
\hline \begin{tabular}{l} 
Mean second formant frequency /i/ Bengali fast rate \\
\hline
\end{tabular} & 10 & 1563.2680 & 294.03000 & 16.813 & .000 \\
\hline
\end{tabular}

The above table indicates that the there is a significant difference between second formant frequency of /i/ in Bengali normal and fast rate

Table 2.5 Comparison of vowel formant frequency (mf1) of /u/ in normal and fast rate in Bengali

\begin{tabular}{|l|r|r|r|r|r|}
\hline \multicolumn{7}{|c|}{ One-Sample Statistics } & Mean & $\begin{array}{c}\text { Std. } \\
\text { Deviation }\end{array}$ & t & $\begin{array}{c}\text { Sig. } \\
\text { (2-tailed) }\end{array}$ \\
\hline $\begin{array}{l}\text { Mean first formant frequency /u/ Bengali normal } \\
\text { rate }\end{array}$ & 10 & 454.2670 & 81.12285 & 17.708 & .000 \\
\hline Mean first formant frequency /u/ Bengali fast rate & 10 & 470.3230 & 90.26332 & 16.477 & .000 \\
\hline
\end{tabular}

The above table indicates that the there is a significant difference between first formant frequency of /u/ in Bengali normal and fast rate

Table 2.6 Comparison of vowel formant frequency $(\mathrm{mf} 2)$ of $/ \mathrm{u} / \mathrm{in}$ normal and fast rate in Bengali

\begin{tabular}{|c|c|c|c|c|c|}
\hline \multicolumn{5}{|c|}{ One-Sample Statistics } & \multirow[b]{2}{*}{$\begin{array}{l}\text { Sig. } \\
\text { (2-tailed) }\end{array}$} \\
\hline & $\mathbf{N}$ & Mean & $\begin{array}{c}\text { Std. } \\
\text { Deviation }\end{array}$ & $\mathbf{t}$ & \\
\hline Mean second formant frequency /u/ Bengali fast rate & 10 & 1240.9500 & 146.35507 & 23.424 & .000 \\
\hline Mean second formant frequency $/ \mathrm{u} /$ Bengali normal rate & 10 & 2025.7090 & 114.64773 & 86.397 & .000 \\
\hline
\end{tabular}

The above table indicates that the there is a significant difference between second formant frequency of $/ \mathrm{u} / \mathrm{in}$

Bengali normal and fast rate 
Objective 3: To document differences in vowel acoustics in varying speaking rate in Tamil and Bengali Table 3.1 Comparison of vowel formant frequency (mf1) of /a/ in normal rate in Bengali and Tamil

\begin{tabular}{|c|c|c|c|c|c|}
\hline \multicolumn{6}{|c|}{ One-Sample Statistics } \\
\hline & $\mathbf{N}$ & Mean & $\begin{array}{c}\text { Std. } \\
\text { Deviation }\end{array}$ & $\mathbf{t}$ & $\begin{array}{l}\text { Sig. } \\
\text { (2-tailed) }\end{array}$ \\
\hline Mean first formant frequency /a/ Bengali normal rate & 10 & 626.6340 & 40.66656 & 48.728 & .000 \\
\hline Mean first formant frequency /a/ Tamil normal rate & 10 & 683.8620 & 84.97163 & 25.450 & .000 \\
\hline
\end{tabular}

The above table indicates that the there is a significant difference between first formant frequency of /a/ in Bengali and Tamil normal rate

Table 3.2 Comparison of vowel formant frequency $(\mathrm{mf} 2)$ of /a/ in normal rate in Bengali and Tamil One-Sample Statistics

\begin{tabular}{|c|c|c|c|c|c|}
\hline \multicolumn{6}{|c|}{ One-Sample Statistics } \\
\hline & $\mathbf{N}$ & Mean & $\begin{array}{c}\text { Std. } \\
\text { Deviation }\end{array}$ & $\mathbf{t}$ & $\begin{array}{c}\text { Sig. } \\
\text { (2-tailed) }\end{array}$ \\
\hline Mean second formant frequency /a/ bengali normal rate & 10 & 1575.2700 & 247.74999 & 20.107 & .000 \\
\hline Mean second formant frequency /a/ tamil normal rate & 10 & 1864.4320 & 246.16291 & 23.951 & .000 \\
\hline
\end{tabular}

The above table indicates that the there is a significant difference between second formant frequency of /a/ in Bengali and Tamil normal rate

Table 3.3 Comparison of vowel formant frequency (mf1) of /i/ in normal rate in Bengali and Tamil

\begin{tabular}{|l|c|r|r|r|r|}
\hline & \multicolumn{5}{|c|}{ One-Sample Statistics } \\
\hline & N & Mean & Std. Deviation & t & Sig. (2tailed) \\
\hline Mean first formant frequency /i/ bengali normal rate & 10 & 406.0300 & 28.92362 & 44.392 & .000 \\
\hline Mean first formant frequency /i/ tamil normal rate & 10 & 567.2090 & 91.70438 & 19.559 & .000 \\
\hline
\end{tabular}

The above table indicates that the there is a significant difference between first formant frequency of /i/ in Bengali and Tamil normal rate

Table 3.4 Comparison of vowel formant frequency (mf2) of /i/ in normal rate in Bengali and Tamil

\begin{tabular}{|l|c|c|c|c|c|}
\hline \multicolumn{2}{|c|}{ One-Sample Statistics } & Mean & $\begin{array}{c}\text { Std. } \\
\text { Deviation }\end{array}$ & t & $\begin{array}{c}\text { Sig. } \\
\text { (2-tailed) }\end{array}$ \\
\hline Mean second formant frequency /i/ bengali normal rate & 10 & 1651.0100 & 312.49287 & 16.707 & .000 \\
\hline Mean second formant frequency /i/ tamil normal rate & 10 & 2048.4250 & 105.80053 & 61.225 & .000 \\
\hline
\end{tabular}

The above table indicates that the there is a significant difference between second formant frequency of /i/ in

Bengali and Tamil normal rate

Table 3.5 Comparison of vowel formant frequency (mf1) of /u/ in normal rate in Bengali and Tamil

\begin{tabular}{|l|r|r|r|r|r|}
\hline \multicolumn{7}{|c|}{ One-Sample Statistics } & \multicolumn{1}{|c|}{ Std. } & $\begin{array}{c}\text { Sig. } \\
\text { (2-tailed) }\end{array}$ \\
\hline Mean first formant frequency /u/ bengali normal rate & 10 & 454.2670 & 81.12285 & 17.708 & .000 \\
\hline Mean first formant frequency /u/ tamil normal rate & 10 & 596.8590 & 107.17629 & 17.611 & .000 \\
\hline
\end{tabular}

The above table indicates that the there is a significant difference between first formant frequency of $/ \mathrm{u} / \mathrm{in}$ Bengali and Tamil normal rate 
Table 3.6 Comparison of vowel formant frequency $(\mathrm{mf} 2)$ of /u/ in normal rate in Bengali and Tamil One-Sample Statistics

\begin{tabular}{|l|r|r|r|r|r|}
\hline & N & Mean & $\begin{array}{c}\text { Std. } \\
\text { Deviation }\end{array}$ & $\begin{array}{c}\text { T } \\
\text { (2-tailed) }\end{array}$ \\
\hline Mean second formant frequency /u/ bengali normal rate & 10 & 1328.7900 & 179.38839 & 23.424 & .000 \\
\hline Mean second formant frequency /u/ tamil normal rate & 10 & 2031.5110 & 74.35716 & 86.397 & .000 \\
\hline
\end{tabular}

The above table indicates that the there is a significant difference between second formant frequency of $/ \mathrm{u} / \mathrm{in}$ Bengali and Tamil normal rate

Table 3.7 Comparison of vowel formant frequency $(\mathrm{mf1})$ of /a/ in fast rate in Bengali and Tamil

\begin{tabular}{|c|c|c|c|c|c|}
\hline \multicolumn{6}{|c|}{ One-Sample Statistics } \\
\hline & $\mathbf{N}$ & Mean & $\begin{array}{c}\text { Std. } \\
\text { Deviation }\end{array}$ & $\mathbf{t}$ & $\begin{array}{c}\text { Sig. } \\
\text { (2-tailed) }\end{array}$ \\
\hline Mean first formant frequency /a/ bengali fast rate & 10 & 584.3120 & 46.34369 & 39.871 & .000 \\
\hline Mean first formant frequency /a/ tamil fast rate & 10 & 1180.1870 & 1740.56682 & 2.144 & .061 \\
\hline
\end{tabular}

The above table indicates that the there is a significant difference between first formant frequency of /a/ in Bengali and Tamil fast rate

Table 3.8 Comparison of vowel formant frequency $(\mathrm{mf} 2)$ of /a/ in fast rate in Bengali and Tamil One-Sample Statistics

\begin{tabular}{|l|r|r|r|r|r|}
\hline \multicolumn{7}{|c|}{ One-Sample Statistics } & Mean & $\begin{array}{c}\text { Std. } \\
\text { Deviation }\end{array}$ & T & $\begin{array}{c}\text { Sig. } \\
\text { (2-tailed) }\end{array}$ \\
\hline Mean second formant frequency /a/ bengali fast rate & $\mathbf{N}$ & 10 & 1571.1400 & 176.57736 & 28.137 \\
\hline Mean second formant frequency /a/ tamil fast rate & 10 & 1887.4250 & 250.41870 & 23.834 & .000 \\
\hline
\end{tabular}

The above table indicates that the there is a significant difference between second formant frequency of /a/ in Bengali and Tamil fast rate

Table 3.9 Comparison of vowel formant frequency $(\mathrm{mf1})$ of /i/ in fast rate in Bengali and Tamil

\begin{tabular}{|c|c|c|c|c|c|}
\hline \multicolumn{5}{|c|}{ One-Sample Statistics } & \multirow[b]{2}{*}{$\begin{array}{c}\text { Sig. } \\
\text { (2-tailed) }\end{array}$} \\
\hline & $\mathbf{N}$ & Mean & $\begin{array}{c}\text { Std. } \\
\text { Deviation }\end{array}$ & $\mathbf{t}$ & \\
\hline Mean first formant frequency /i/ bengali fast rate & 10 & 415.1300 & 22.42514 & 58.540 & .000 \\
\hline Mean first formant frequency $/ \mathrm{i} /$ tamil fast rate & 10 & 546.5750 & 57.18234 & 30.226 & .000 \\
\hline
\end{tabular}

The above table indicates that the there is a significant difference between first formant frequency of /i/ in

Bengali and Tamil fast rate

Table 3.10 Comparison of vowel formant frequency $(\mathrm{mf} 2)$ of $/ \mathrm{i} / \mathrm{in}$ fast rate in Bengali and Tamil One-Sample Statistics

\begin{tabular}{|c|c|c|c|c|c|}
\hline \multicolumn{6}{|c|}{ One-Sample Statistics } \\
\hline & $\mathbf{N}$ & Mean & $\begin{array}{c}\text { Std. } \\
\text { Deviation }\end{array}$ & $\mathbf{t}$ & $\begin{array}{c}\text { Sig. } \\
\text { (2-tailed) }\end{array}$ \\
\hline Mean second formant frequency /i/ bengali fast rate & 10 & 1563.2680 & 294.03000 & 16.813 & .000 \\
\hline Mean second formant frequency /i/ tamil fast rate & 10 & 2057.9500 & 131.98264 & 49.308 & .000 \\
\hline
\end{tabular}

The above table indicates that the there is a significant difference between second formant frequency of /i/ in Bengali and Tamil normal rate 
Table 3.11 Comparison of vowel formant frequency $(\mathrm{mf} 1)$ of $/ \mathrm{u} / \mathrm{in}$ fast rate in Bengali and Tamil One-Sample Statistics

\begin{tabular}{|l|c|c|c|r|}
$\mathbf{N}$ & Mean & $\begin{array}{c}\text { Std. } \\
\text { Deviation }\end{array}$ & t & \multicolumn{1}{|c|}{$\begin{array}{c}\text { Sig. } \\
\text { (2-tailed) }\end{array}$} \\
\hline 10 & 470.3230 & 90.26332 & 16.477 & .000 \\
\hline 10 & 614.6500 & 154.68065 & 12.566 & .000 \\
\hline
\end{tabular}

The above table indicates that the there is a significant difference between first formant frequency of $/ \mathrm{u} /$ in Bengali and Tamil fast rate

Table 3.12 Comparison of vowel formant frequency $(\mathrm{mf} 2)$ of $/ \mathrm{u} / \mathrm{in}$ fast rate in Bengali and Tamil One-Sample Statistics

\begin{tabular}{|l|c|c|c|c|c|}
\hline & N & Mean & $\begin{array}{c}\text { Std. } \\
\text { Deviation }\end{array}$ & $\begin{array}{c}\text { Sig. } \\
\text { t } \\
\text { tailed) }\end{array}$ \\
\hline Mean second formant frequency /u/ bengali fast rate & 10 & 1240.9500 & 146.35507 & 26.813 & .000 \\
\hline Mean second formant frequency /u/ tamil fast rate & 10 & 2025.7090 & 114.64773 & 55.874 & .000 \\
\hline
\end{tabular}

The above table indicates that the there is a significant difference between second formant frequency of $/ \mathrm{u} / \mathrm{in}$ Bengali and Tamil fast rate

\section{Objective 4}

To document differences in non-similar vowel acoustics in varying speaking rate in Bengali and Tamil Table 4.1 Comparison of different vowel formant frequency $(\mathrm{mf} 1)$ of $/ \mathrm{s} / \mathrm{in}$ normal and fast rate in Bengali

\begin{tabular}{|c|c|c|c|c|c|}
\hline \multicolumn{6}{|c|}{ One-Sample Statistics } \\
\hline & $\mathbf{N}$ & Mean & $\begin{array}{c}\text { Std. } \\
\text { Deviation }\end{array}$ & $\mathbf{T}$ & $\begin{array}{l}\text { Sig. }(2- \\
\text { tailed })\end{array}$ \\
\hline $\begin{array}{l}\text { Mean first formant frequency different bengali } \\
\text { normal rate }\end{array}$ & 10 & 581.9200 & 27.52041 & 66.866 & .000 \\
\hline $\begin{array}{l}\text { Mean first formant frequency different bengali fast } \\
\text { rate }\end{array}$ & 10 & 582.0330 & 41.37235 & 44.487 & .000 \\
\hline
\end{tabular}

The above table indicates that the there is a significant difference between first formant frequency of non-similar vowel / $\mathrm{s}$ / in Bengali normal and fast rate

Table 4.2 Comparison of different vowel formant frequency $(\mathrm{mf} 2)$ of $/ \mathrm{s} / \mathrm{in}$ normal and fast rate in Bengali

\begin{tabular}{|l|c|c|c|c|c|}
\hline \multicolumn{7}{|c|}{ One-Sample Statistics } & Mean & $\begin{array}{c}\text { Std. } \\
\text { Deviation }\end{array}$ & $\begin{array}{c}\text { Sig. (2- } \\
\text { tailed) }\end{array}$ \\
\hline $\begin{array}{l}\text { Mean second formant frequency different bengali } \\
\text { normal rate }\end{array}$ & 10 & 1252.0400 & 145.27507 & 27.254 & .000 \\
\hline $\begin{array}{l}\text { Mean second formant frequency different bengali } \\
\text { fast rate }\end{array}$ & 10 & 1270.5700 & 100.44637 & 40.000 & .000 \\
\hline
\end{tabular}

The above table indicates that the there is a significant difference between second formant frequency of non-similar vowel / $\mathrm{s}$ / in Bengali normal and fast rate 
Table 4.3 Comparison of different vowel formant frequency $(\mathrm{mf} 1)$ of / $\mathrm{\Lambda} /$ in normal and fast rate in Tamil

\begin{tabular}{|l|c|c|c|c|c|}
\hline \multicolumn{7}{|c|}{ One-Sample Statistics } & Mean & $\begin{array}{c}\text { Std. } \\
\text { Deviation }\end{array}$ & T & $\begin{array}{c}\text { Sig. (2- } \\
\text { tailed) }\end{array}$ \\
\hline $\begin{array}{l}\text { Mean first formant frequency different Tamil normal } \\
\text { rate }\end{array}$ & 10 & 612.2880 & 94.36566 & 20.518 & .000 \\
\hline Mean first formant frequency different Tamil fast rate & 10 & 619.6100 & 58.98875 & 33.216 & .000 \\
\hline
\end{tabular}

The above table indicates that the there is a significant difference between first formant frequency of non-similar vowel / $\Lambda$ in Tamil normal and fast rate

Table 4.4 Comparison of different vowel formant frequency $(\mathrm{mf} 2)$ of $/ \Lambda /$ in normal and fast rate in Tamil

\begin{tabular}{|l|c|c|c|c|c|}
\hline \multicolumn{2}{|c|}{ One-Sample Statistics } & Mean & \multicolumn{1}{|c|}{$\begin{array}{c}\text { Std. } \\
\text { Deviation }\end{array}$} & $\begin{array}{c}\text { T } \\
\text { Sig. (2- } \\
\text { tailed) }\end{array}$ \\
\hline $\begin{array}{l}\text { Mean second formant frequency different tamil } \\
\text { normal rate }\end{array}$ & 10 & 2466.7940 & 1913.96663 & 4.076 & .003 \\
\hline $\begin{array}{l}\text { Mean second formant frequency different tamil fast } \\
\text { rate }\end{array}$ & 10 & 1877.0730 & 276.23307 & 21.488 & .000 \\
\hline
\end{tabular}

The above table indicates that the there is a significant difference between second formant frequency of nonsimilar vowel $/ \Lambda /$ in Tamil normal and fast rate.

\section{Objective 5}

To compare of mean rate of speech in varying speaking rate in Bengali and Tamil

Table 5.1 Comparison of mean rate of speech in varying speaking rate in Bengali and Tamil

\begin{tabular}{|c|c|c|c|c|}
\hline Participants & BNR & BFR & TNR & TFR \\
\hline 1 & 7.41 & 4.47 & 7.57 & 4.44 \\
\hline 2 & 7.52 & 4.21 & 5.58 & 4.39 \\
\hline 3 & 7.05 & 4.38 & 5.65 & 3.75 \\
\hline 4 & 7.86 & 5.27 & 6.7 & 4.96 \\
\hline 5 & 7.51 & 4.13 & 7.51 & 5.44 \\
\hline 6 & 7.58 & 4.56 & 7.86 & 5.9 \\
\hline 7 & 8.33 & 5.24 & 9.62 & 6.33 \\
\hline 9 & 7.82 & 5.13 & 9.79 & 5.75 \\
\hline 10 & 7.33 & 4.42 & 8.02 & 5.94 \\
\hline Mean Rate of Speech & 8.42 & 5.08 & 7.35 & 4.5 \\
\hline
\end{tabular}

*BNR-Bengali Normal Rate; BFR-Bengali Fast Rate; TNR-Tamil Normal Rate; TFR-Tamil Fast Rate

The rate of speech values are of BNR/BFR and TNR/TFR is fed as follows: Participant 1 who is a native bengali speaker had taken 7.41 minutes/225 syllables in Bengali normal rate of speech and 4.21 minutes/225 syllables in Bengali fast rate of speech. In the same way, Participant 1 who is native Tamil speaker had taken 7.57 minutes/372 syllables in Tamil normal rate of speech and 4.44 minutes/372 syllables in Tamil fast rate of speech. Thus, the above table indicates that the mean rate of speech in Bengali and Tamil showed higher duration to read the passage in normal than fast rate. 


\section{DISCUSSION}

Vowels can differ in acoustic analysis in various aspects because the speech code varies with language, dialect, age, sex and specific physiological constraints of the speaker (Fant,2004). In the current study, we attempted to understand the acoustical differences in two different languages, Tamil and Bengali which belongs to two different language family, Dravidian and Indo-Aryan respectively. We introduced reading passages in the mentioned languages for understanding the differences in first and second formant frequencies of vowels extracted from the reading samples.

The results showed that there is a significant difference between first and second formant frequency of similar vowels /a/, /i/, /u/ in Bengali and Tamil in varying speaking rate. We also compared non-similar vowels in these two languages finding that there is significant difference between first and second formant frequency of non-similar vowels $/ \mathrm{J} /$ in Bengali and vowel $/ \Lambda /$ Tamil in varying speaking rate. By documenting the differences in formant frequencies in varying speaking rate we are able to understand that rate makes an important difference in formant frequencies which is again also the influenced by the language spoken.

Thus, in this study it is proved that there would be changes in vowel acoustics with changes in rate of speech and it is clinically important to investigate the language specific rate of speech in individuals when we are assessing conversational discourse or reading sample for acoustical analysis. Further research in larger population might be needed for extensive information on the same.

It is known that the intertalker variability of the vowel spaces was found to be greater for slow talkers than the fast talkers for both males and females (Dietrich, 2019). We sought to understand if this holds good with different languages and different speaking rate in this study and found that the mean rate of speech in Bengali and Tamil was higher in duration when the passage was in normal rate than fast rate.

\section{CONCLUSION}

Vowel formant frequencies are among the most frequently reported acoustic measures of speech and are used in a variety of applications including automatic speech recognition, studies of speech production and speech perception in various populations of speakers, and clinical assessments in a range of speech, voice, and language disorders. In the present study that aimed at representing the influence of rate of speech on vowels acoustics in two different languages - Bengali (Indo-Aryan) and Tamil (Dravidian) by comparing the mean formant frequencies ( $\mathrm{mf} 1$ and $\mathrm{mf} 2$ ) of vowels of $/ \mathrm{a} /, / \mathrm{i} /$ and $/ \mathrm{u} /$ in two different languages Tamil and Bengali in normal and fast speaking rate, we found that there is a significant difference in one sample $\mathrm{t}$ - test. Results also indicated that there is a significant difference between formant frequencies of non-similar vowel $/ \mathrm{J} /$ in Bengali normal and fast rate and $/ N$ in tamil normal and fast rate. Results of differences in vowel acoustics in varying speaking rate in Tamil and Bengali that the mean rate of speech in Bengali and Tamil showed higher duration to read the passage in normal than fast rate.

\section{REFERENCES}

1. Kent, R. D., \& Vorperian, H. K. (2018). Static measurements of vowel formant frequencies and bandwidths: A review. Journal of communication disorders, 74, 74-97.

2. Perrier, P. (2005). Control and representations in speech production. ZAS Papers in Lingustics, 40, 109-132.

3. Tsao, Y. C., Weismer, G., \& Iqbal, K. (2006). The effect of intertalker speech rate variation on acoustic vowel space. The Journal of the Acoustical Society of America, 119(2), 1074-1082.

4. Fant, G. (2004). Speech acoustics and phonetics: Selected writings (Vol. 24). Springer Science \& Business Media.

5. Mefferd, A. S., \& Dietrich, M. S. (2019). Tongue-and jaw-specific articulatory underpinnings of reduced and enhanced acoustic vowel contrast in talkers with Parkinson's disease. Journal of Speech, Language, and Hearing Research, 62(7), 2118-2132. 